Editorial

\title{
Vale la pena leer este volumen
}

\section{Its Worth reading this Volume}

\author{
David Figueroa P. ${ }^{1}$ \\ ${ }^{1}$ Departamento de Ortopedia y Traumatología, Clínica Alemana, \\ Santiago, Chile
}

Rev Chil Ortop Traumatol 2017;58:77.

Este volumen de la revista RCHOT, es posiblemente uno de los más interesantes del año 2017, ya que reúne una gama de artículos de alto nivel, producto del estudio y trabajo de nuestros colegas.

Partiendo del estudio biomecánico que nos presenta el Dr. Alex Vaisman y col., con una metodología simple, pero con un trabajo importante y con conclusiones que sin duda aportan al trabajo clínico que realizamos los cirujanos de Rodilla, sobre las lesiones del tendón patelar.

El siguiente estudio muestra una comparación entre lesiones de ligamento con lesiones osteocondrales y aquellas que no la tienen, mostrando claramente que la funcionalidad en el tiempo de los pacientes que presentan lesiones condrales asociadas, es claramente inferior a la de los pacientes que no las tienen.

El próximo estudio, liderado por el Dr. Liendo y cols., muestra un grupo de pacientes con fractura clavicular, tratados con una técnica específica mínimamente invasiva, con buenos y excelentes resultados funcionales. Aquí se hace hincapié en la técnica quirúrgica.
El Dr. Mendez y col. en el siguiente estudio publicado, nos muestran una prolija y cuidadosa técnica quirúrgica que reconstruye el pulgar, restableciendo la pinza anatómica en niños, que logran buena funcionalidad y estética con el tiempo.

En el siguiente estudio publicado el Dr. Calvo y cols., nos presentan un caso clínico de una lesión condral extensa, tratada con técnica biológica, y en la cual se adhieren injerto óseo, membrana de colágeno y concentrado de médula ósea, aplicados a un defecto osteocondral profundo, con buenos resultados a mediano plazo.

Finalmente, el Dr. Gallero y cols. Nos muestran un caso clínico con fractura de alta energía de platillo tibial que evoluciona con valgo severo, manejado con osteotomía de cierre medial de tibia proximal, corrigiendo la deformidad angular, con buen resultado clínico y funcional.

Es un volumen completo, con diversas modalidades de publicación, y con todos los trabajos muy interesantes, que promueven la lectura científica y muestran el gran potencial que tiene nuestra Revista en un futuro cercano.
Address for correspondence David Figueroa P., MD, PhD, Director, Revista Chilena de Ortopedia y Traumatología; Departamento de Ortopedia y Traumatología, Clínica Alemana, Santiago, Chile

(e-mail: dhfigueroa@gmail.com).
DOI https://doi.org/ 10.1055/s-0037-1617755. ISSN 0716-4548.
Copyright @ 2017 by Thieme Revinter Publicações Ltda, Rio de Janeiro, Brazil

\section{Unementement \\ ()(1) $\Theta \circledast$}

